\author{
By: \\ R.C. Zowarka \\ J.P. Kajs
}

Digest of Technical Papers, 8th Pulsed Power Conference, San Diego, CA, June 16-19, 1991, pp. 267

PN - 188

Center for Electromechanics

The University of Texas at Austin

PRC, Mail Code R7000

Austin, TX 78712

(512) 471-4496 


\title{
25 GW HOMOPOLAR GENERATOR EXPERIMENT
}

\author{
R.C. Zowarka and J.P Kajs \\ The University of Texas at Austin \\ Center for Electromechanics \\ Balcones Research Center \\ Austin, TX 78712 \\ (512) $471-4496$
}

\begin{abstract}
Early in the design iterations for the Balcones $60 \mathrm{MJ}$ power supply different options were considered, from a single machine to modular homopolar generators (HPGs).[1] A multiple machine option was chosen to provide greater system flexibility. Envisioned uses for the power supply were to weld up to $100 \mathrm{in} .2$ of metal, heat a $100 \mathrm{lb}$ steel billet to forging temperature in 2 to $4 \mathrm{~s}$, and conduct high level electromagnetic gun experiments.[2] A study involving detailed computer optimization compared drum type HPGs to disk type machines. For fixed location (such as large proof of principle laboratory experiments) the higher energy transfer efficiency and lower cost per joule delivered made the drum configuration more attractive. The compact disk design was better for mobile applications where minimum mass is the primary consideration. [3] The six drum HPGs installed in the underground hexagonal pit in the Balcones lab are shown in figure 1.
\end{abstract}

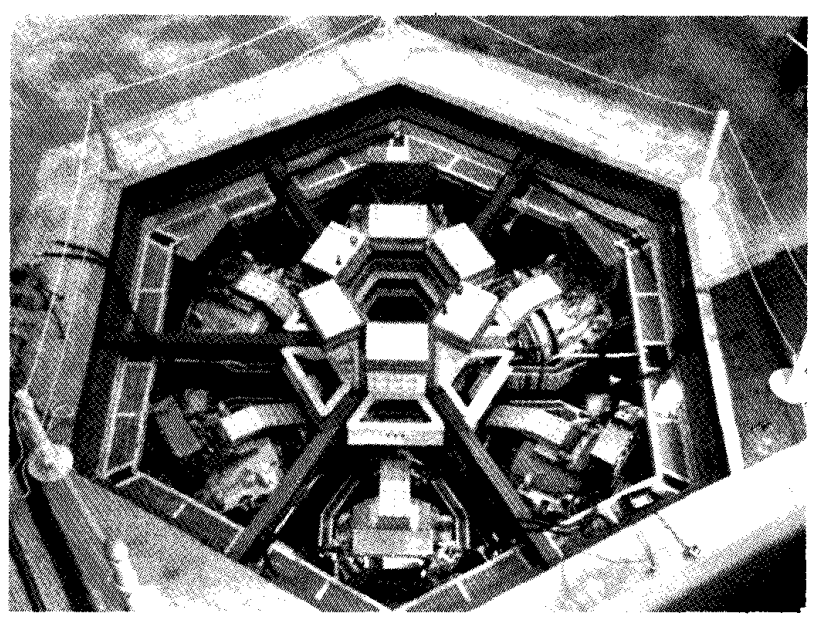

Figure 1. Balcones homopolar generator power supply

\section{Introduction}

The University of Texas Balcones power supply consists of six, $10 \mathrm{MJ}$ HPGs charging six energy storage inductors, each at a peak charging current of 1.25 MA. The operation of the HPG/inductor can be seen in the simple circuit diagram presented in figure 2. The HPG is a low voltage pulsed generator with extremely low internal impedance. Operationally the HPG is motored to speed and then the generators field coil is energized to produce terminal voltage. At this time a switch is closed and the
HPG charges the inductor through an explosive opening switch. The switch mounted in the charging buswork is simply a solid conducting plate prepared with specially designed grooves in which explosive primer cord is loaded. In the pulsed discharge mode the HPG models electrically as a capacitor, and the discharge into the inductor is an underdamped response in which the current rises in a sinusoidal fashion to a peak value in hundreds of milliseconds. At peak current the primer cord in the switch is detonated with safe, noise immune exploding bridgewire detonators (EBWs). As the buswork is cut open, the resistance of that path increases rapidly (10 to $200 \mu \mathrm{s})$ developing a high voltage that then commutates the inductors current into the load. In this circuit the inductor acts as a pulse compression device in which the magnetically stored energy is rapidly converted to an electrical pulse to energize the load.

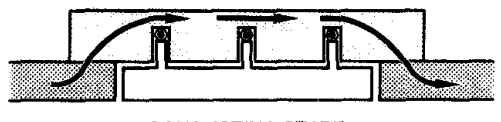

CONDUCTING STATE

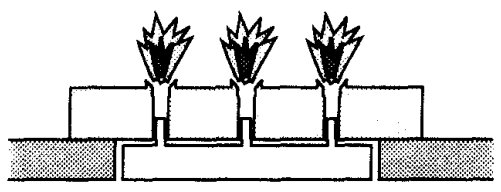

OPENED STATE

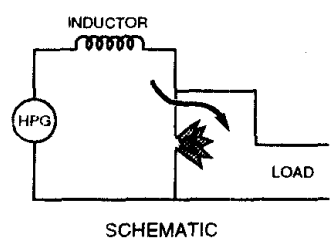

1001.0642

Figure 2. Explosive opening switch, circuit operation

To provide the intermediate energy storage and pulse compression as required by HPG driven railgun accelerators, six inductors were designed and built. [4] The design criteria for the inductors called for a $50 \%$ transfer efficiency, or $5 \mathrm{MJ}$ at 1.25 MA from the HPG. A two turn coaxial geometry (fig. 3) was chosen because of the minimal external fields associated with coax's and the ability to utilize high dielectric strength insulation and replace the insulation if required. However, because the inductance is proportional to the number of turns squared, limiting the design to two turns resulted in rather large and heavy devices. 


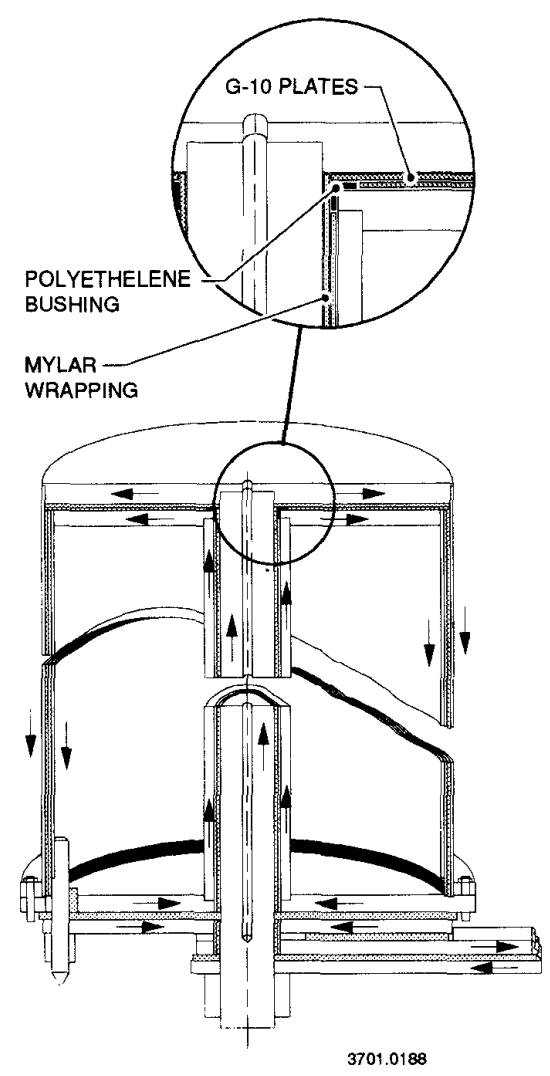

Figure 3. Cross section of two turn coaxial inductor

Flexibility is achieved by selecting a particular speed for the generators and then staging the discharge to produce waveforms of a certain peak current and pulse duration. The system block diagram is shown in figure 4. There are two phases to the discharge. All six homopolar generators are brought up to speed over 2 min and then the excitation fields are turned on. This produces terminal voltage at the generators. The brushes on all six generators are then lowered to initiate the electrical discharge. Currents rise in all six inductors over a $150 \mathrm{~ms}$ time frame. The current waveforms of each HPG inductor have a 10 to $20 \mathrm{~ms}$ flat top about peak current. It is during this interval that the staged railgun discharge is initiated. Explosive switch 1 is detonated and isolation switch 1 is closed. Current from storage inductor 1 is commutated into the railgun. All other isolation switches are open at this time so the other charged energy stores do not communicate with the gun. Conversely the switched stores communicate only with the railgun and not with the remaining short circuit opening switches. Subsequent stores will switch in their current according to preprogrammed delays, thus allowing different current waveforms to be generated. When subsequent stores discharge, the current transfers into the railgun and not into previously discharged energy stores due to the developed insulation strength in the previously opened switch and the large reactive impedance of the inductive energy store itself.

The remainder of the paper will describe the high energy high power experiments that have been performed
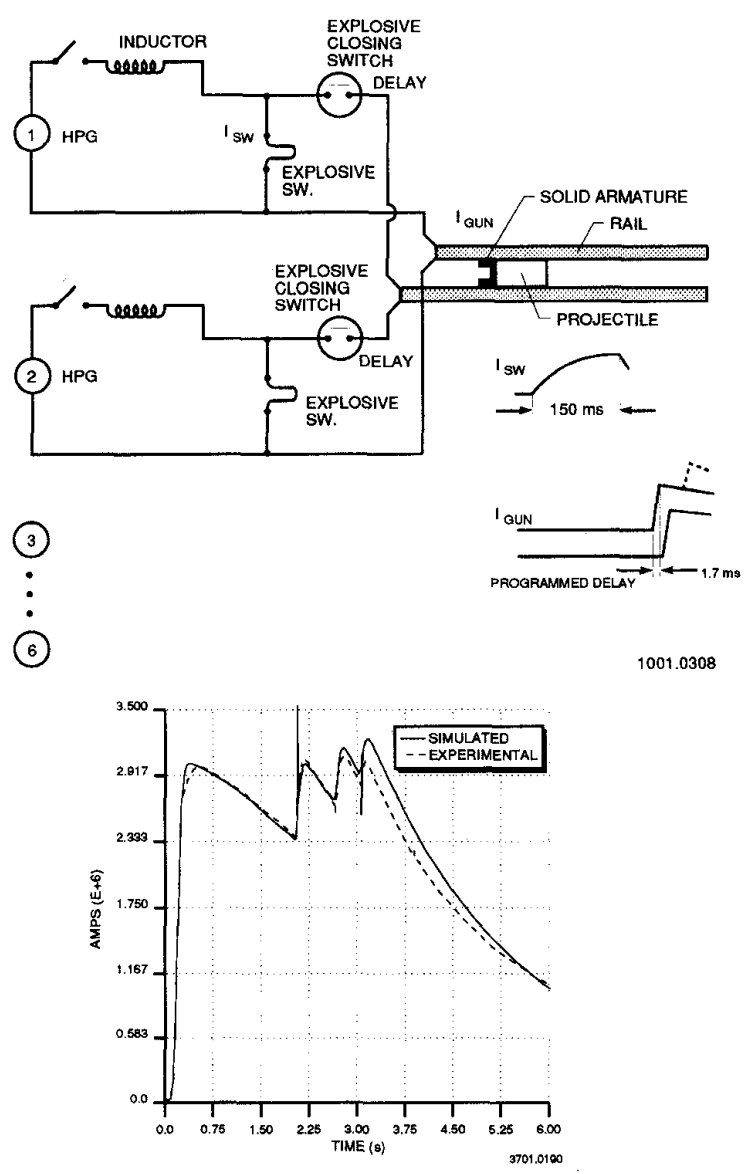

Figure 4. Staged operation of power supply

with the power supply and future pulsed power experiments that will utilize the unique capabilities of the facility.

\section{High Power Railgun Experiments}

On February 23, 1990 the Balcones power supply was used to power a $90 \mathrm{~mm}$ bore railgun to launch a $2.4 \mathrm{~kg}$ $(5.3 \mathrm{lb})$ aluminum projectile to a velocity of $2.6 \mathrm{~km} / \mathrm{s}(8,500$ $\mathrm{ft} / \mathrm{s})$. At eight million joules of kinetic energy, this is one of the highest energies ever achieved by an electromagnetic gun.

Critical aspects of the experiment included staged discharge of the generators at 25,000 MW and successful performance of the solid armature which transported the 3-MA current from one rail of the railgun to the other (fig. 5). The CEM-UT program has shown that solid armatures increase launch efficiency and substantially reduce bore damage. High speed photographs show that the payload was launched intact and flew straight down the $150 \mathrm{ft}$ deep vertical aeroballistic range. The staged waveform predicted by the simulation code and the actual experimentally measured current are presented in figure 6 .

To date a total of 70 railgun tests have been done on the system. There have been 18 small caliber (12 to 25 $\mathrm{mm}$ ) hypervelocity tests, 15 tests with the $45 \mathrm{~mm}$ hydraulically preloaded ceramic gun, and 37 tests with the $90 \mathrm{~mm}$ hydraulically preloaded ceramic single shot gun. 


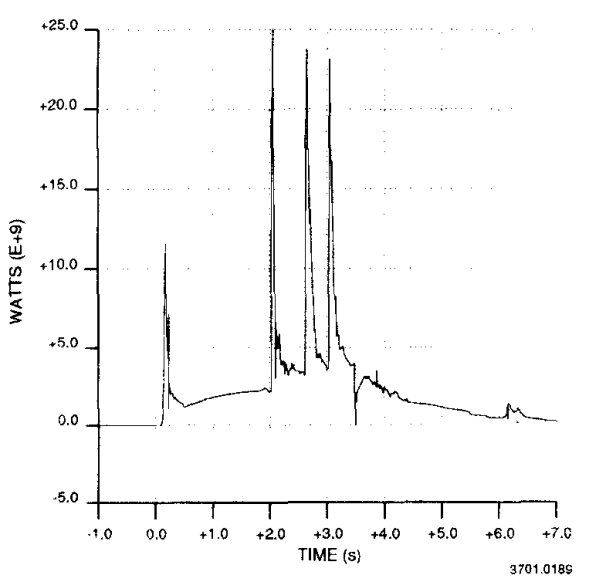

Figure 5. Railgun breech power

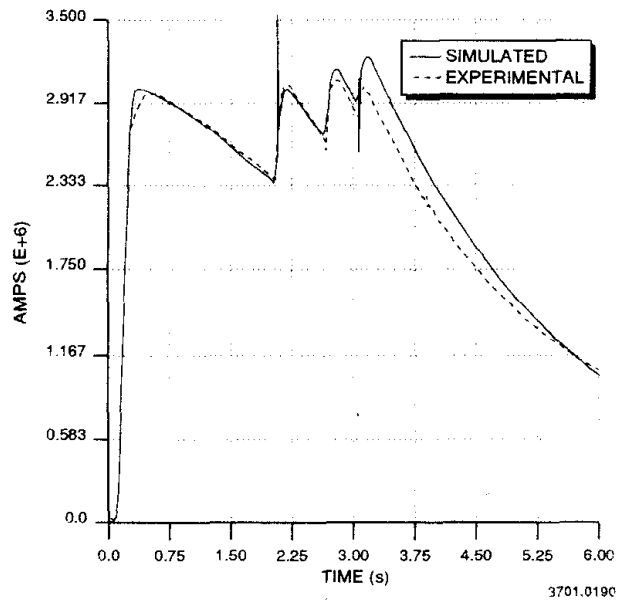

Figure 6. Staged current waveforms simulated and measured

\section{Toroidal Field Magnet Experiment}

In another program CEM-UT has designed, built, and operated a 1/16 scale IGNITEX [5] toroidal field (TF) magnet. The prototype, high field, TF magnet is powered by the Balcones power supply in a different circuit topology than used with the railgun experiments. In this system each HPG is connected directly to a segment of the toroidal magnet (fig. 7). Single turn magnets permit maximum efficiency in the production of toroidal magnetic field because of the elimination of electrical insulation. In addition, the HPGs inherently low voltage and high currents are ideally suited to fulfill the requirements of the single turn magnet. Figure 8 shows HPG currents and voltages for a discharge which produced $15 \mathrm{~T}$ in the bore of the magnet.

Synchronization of multiple HPGs into a single-turn toroidal magnet has been realized. To date, the prototype TF magnet has produced up to $18.1 \mathrm{~T}$ on-axis. This world record value in a toroidal configuration has both scientific and technological significance. It is believed that $15 \mathrm{~T}$ is the threshold value for ohmic ignition in a compact tokamak system. The test program is in progress and 21 tests of the magnet have been done to date.

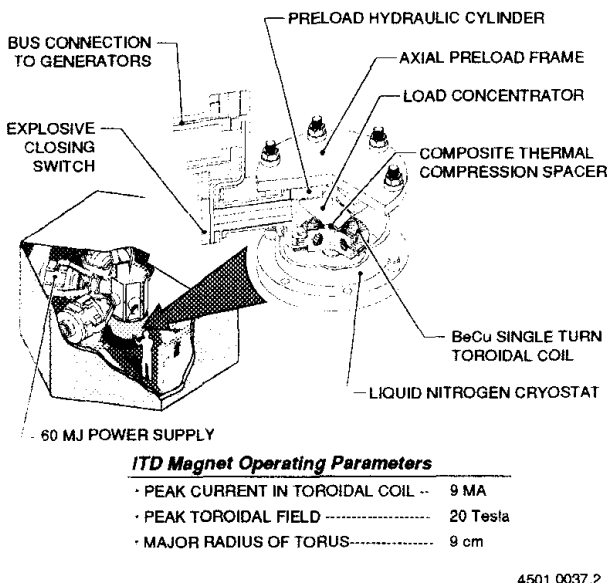

Figure 7. Ignition technology demonstration (ITD)

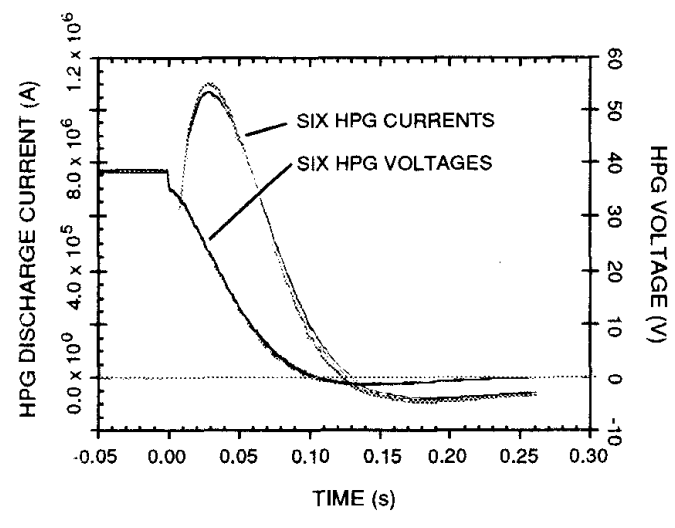

4501.0071

Figure 8. Six HPG voltages and currents for $15 \mathrm{~T}$ (test \#9)

\section{Laser Flash Lamp Experiments}

Future experiments planned for the Balcones power supply involve the pulsed discharge into laser flashlamps. A baseline design of the Nova Upgrade has been completed by Lawrence Livermore National Laboratory.[6] The Nova Upgrade is an 18 beamline Nd:glass laser design utilizing fully relayed $4 \times 430 \mathrm{~cm}$ aperture segmented optical components. The laser thus consists of 288 independent beamlets nominally producing 1.5 to $2.0 \mathrm{MJ}$ of $0.35 \mu \mathrm{m}$ light in a 3 to $5 \mathrm{~ns}$ pulse. The laser design is extremely flexible and will allow a wide range of pulses to irradiate inertial confinement fusion (ICF) targets. The pulsed power requirements for the Nova Upgrade are given in table 1.

Historically the pulsed power supply for the laser amplifiers has been based around large capacitor bank technology. CEM-UT is proposing to study HPG/inductor technology as an alternative pulsed power source with the potential for significant cost savings.

The operation of the HPG/inductor can be seen in the simple circuit diagram presented in figure 2 where the load is now the flashlamp module. As the buswork is cut open the resistance of that path increases rapidly (100 to 
$200 \mu \mathrm{s})$ developing a high voltage that then commutates the inductors current into the flashlamp load. In this circuit the inductor acts as a pulse compression device in which the magnetically stored energy is rapidly converted to an electrical pulse to energize the flashlamp load.

Table 1. Flashlamp pump

Electrical pulsed power supply energy

Electrical pulsed power supply voltage $200 \mathrm{M} s$

Flashlamps per module $20 \mathrm{kV}$

Modules per beamline

48

Bore diameter

Length

Explosion fraction

Gas fill

Pump pulse length

$2.5 \mathrm{~cm}$

130 to $150 \mathrm{~cm}$

0.3

Xenon - 200 torr

$500 \mu \mathrm{s}$

The feasibility of this approach may be demonstrated with simple analysis. The pulsed energy required of the Nova Upgrade system is found by examining the flashlamp parameters. The explosion energy for the lamp is given by the formula,

$$
\mathrm{E}=1.2 \times 10^{4} \times \ell \times \mathrm{d} \times \sqrt{\mathrm{T}}
$$

where

$$
\begin{aligned}
\mathrm{E} & =\text { explosion energy }(\mathrm{J}) \\
\ell & =\text { lamp length }(\mathrm{cm}) \\
\mathrm{d} & =\text { lamp diameter }(\mathrm{cm}) \\
\mathrm{T} & =\text { pulse width }(\mathrm{s})
\end{aligned}
$$

Values from table 1 were substituted into this equation and the explosion energy was calculated to be $87.2 \mathrm{~kJ}$ at a lamp length of $130 \mathrm{~cm}$. The system will be operated at an explosion fraction of 0.3 . When this is factored with the overall description of 18 beamlines, 10 segments per beamline, and 48 lamps per segment the total flashlamp energy requirement is found to be $226 \mathrm{MJ}$.

When an opening switch commutates current into a load there is a fundamental requirement that the switch absorb energy from the system to affect the commutation. The amount of lost energy is determined by the inductance of the load. Explosive opening switches routinely commutate current into electric guns at transfer efficiencies of $80 \%$. The electric gun models as a constant inductance associated with interconnecting buswork plus a time varying inductance which increases with motion down the gun. The flashlamps on the other hand are predominantly resistive with the buswork and cables between the pulsed power source and the lamps contributing a constant inductive component to this load. A conservative value for the transfer efficiency from the energy storage inductor to the flashlamps is therefore $80 \%$. An estimate of the total inductive energy required is therefore $283 \mathrm{MJ}$.

Demonstrated transfer efficiencies from HPG to inductor are nominally $50 \%$. This leads to an HPG stored energy requirement of $565 \mathrm{MJ}$. At this point the total

system current must be estimated to complete the pulsed power specification. The voltage-current characteristic of the flashlamp for the high current region can be represented as

$$
\mathrm{V}= \pm \mathrm{K}_{\mathrm{o}}|\mathrm{i}|^{1 / 2}
$$

where

$$
\begin{aligned}
\mathrm{V} & =\text { flashlamp voltage } \\
\mathrm{i} & =\text { flashlamp current } \\
\mathrm{K}_{0} & =\text { lamp constant }
\end{aligned}
$$

The lamp constant is solely dependent on lamp geometry, gas type, and gas pressure and may be calculated from the equation

$$
\mathrm{K}_{\mathrm{o}}=1.27\left(\frac{\mathrm{P}}{450}\right)^{0.2} \ell / \mathrm{d}
$$

where

$$
\mathrm{P}=\text { lamp pressure (torr) }
$$

Substituting appropriate values from table 1 the lamp constant is found to be $56.15 \Omega-\mathrm{A}^{1 / 2}$. In general the lamps are operated in series pairs to reduce system complexity, balance forces within amplifier segments, and to ease physical connection to the lamps. The expression for the current through a series set of lamps is therefore

$$
i=\left(\frac{V}{2 K_{o}}\right)^{2}
$$

Nominal demonstrated voltage generation capability of the explosive opening switch is $10,000 \mathrm{~V}$. This voltage will produce a current per lamp of 7,929 A, and a current per beamline, 10 segments per amplifier, 24 sets of seriesed pairs of lamps per segment of 1.9 MA. The circuit arrangement of the HPGs, inductive stores, and flashlamp amplifiers is presented in .9 .

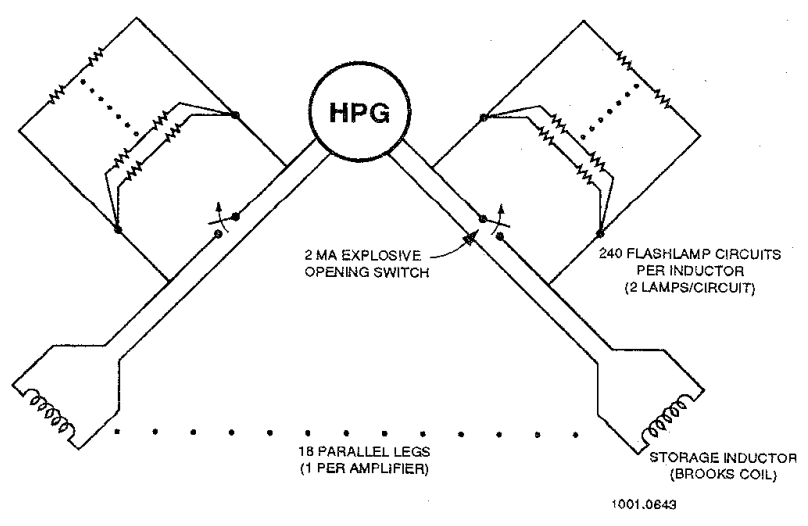

Figure 9. HPG power supply circuit 
To test the feasibility of inductive stores driving flashlamps at this current and energy level, two Balcones modules will be discharged into a laser amplifier to determine the energy transfer efficiency and the current sharing among parallel lamp circuits. A large data base is available for determining the optimal operation of flashlamps driven with capacitive stores. This proposed testing will allow the same information to be determined for inductive stores. A simulation of two Balcones modules discharging into a laser amplifier is presented in figure 10 . The predicted flashlamp performance is presented in figure 11.

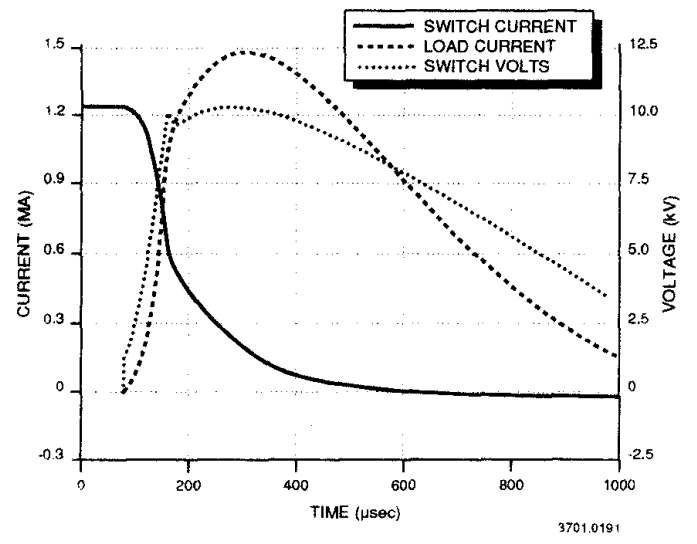

Figure 10. Individual Balcones module performance and total flashlamp current

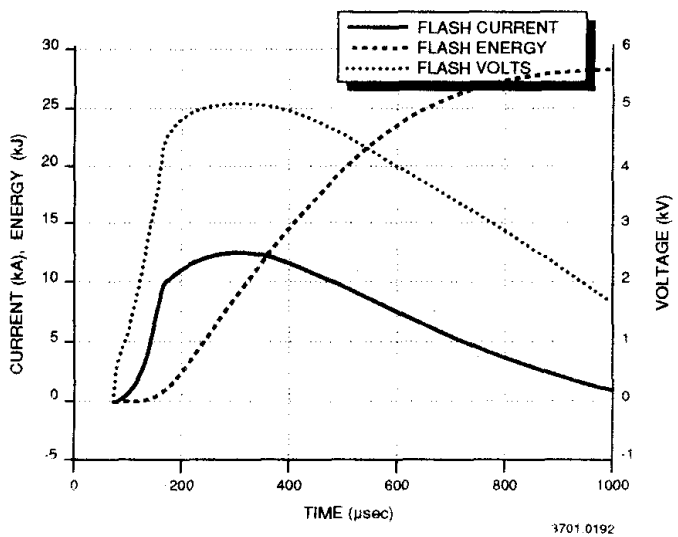

Figure 11. Flashlamp voltage, current, and energy

\section{Conclusions}

The Balcones HPG power supply is a high energy, flexible, robust test bed capable of significant pulsed power research in a wide area of disciplines. Significant experiments have been conducted in railgun research and magnetic confinement fusion. In the near future significant tests are anticipated in the field of inertial confinement fusion. The original industrial applications involving welding and billet heating remain viable applications for the pulsed power supply. The Center for Electromechanics will continue to make the power supply available to the research community and is anticipating continued significant accomplishments in pulsed power research.

This work is sponsored by the U.S. Army ARDEC, DARPA, and the Texas Atomic Energy Research Foundation.

\section{References}

1. W.F. Weldon and T.A. Aanstoos, "The Proposed CEMUT 50-MJ Pulsed Homopolar Generator Power Supply," IEEE Transactions on Magnetics, vol 1 Mag-18, no. 1 , January 1982.

2. W.L. Bird, C.A. Morgan, J.E. Floyd, T.A. Aanstoos, and W.F. Weldon, "The Design of a pulsed Homopolar generator Power Supply for a High Current Laboratory," 4th IEEE Pulsed Power Conference, Albuquerque, New Mexico, 1983.

3. W.L. Bird, D.R. Brown, S.B. Pratap, and W.F. Weldon, "Application of Rotating Electrical Machinery for Charging Capacitive Loads," 4th IEEE Pulsed Power Conference, Albuquerque, New Mexico, 1983.

4. R.L Laughlin, J.H. Gully, K.E. Nalty, and R.C. Zowarka, "System Design of the Ultrahigh Velocity GEDI Experiment," IEEE Transactions on Magnetics, vol Mag-22, no. 6, November 1986.

5. R. Carrera, "Description of the Scientific and Technological Aspects of the Fusion Ignition Experiment IGNITEX," 9th Topical Meeting of the Technology of Fusion Energy, Oak Brook, IL, October 1990.

6. Lawrence Livermore National Laboratory, "LLNL ICF Program Precision Nova and Nova Upgrade Laser," Publication No. UCRL-TB-104288, August 29, 1990. 